\title{
Gestão Participativa Ambiental em Instituições Deliberativas no Território Médio Sertão (PB): Arranjo jurídico-Institucional e do Processo Decisório
}

\author{
Participatory Environmental Management in Deliberative Institutions in the Middle Sertão \\ Territory (PB): Legal-Institutional and Decision-Making Arrangement \\ Gestión ambiental participativa en instituciones deliberativas del territorio del Sertão Medio (PB): \\ ordenamiento jurídico-institucional y de toma de decisiones
}

Recebido: 30/05/2021 | Revisado: 10/06/2021 | Aceito: 14/06/2021 | Publicado: 28/06/2021

\author{
Talita Linhares Soares \\ ORCID: https://orcid.org/0000-0001-9066-1723 \\ Universidade Estadual da Paraíba, Brasil \\ E-mail: talita10lins@gmail.com \\ Thays Santana dos Santos Nascimento \\ ORCID: https://orcid.org/0000-0001-8891-4496 \\ Universidade Estadual da Paraíba, Brasil \\ E-mail: thayssantanasn@gmail.com \\ Lucas Andrade de Morais \\ ORCID: https://orcid.org/0000-0003-4443-2393 \\ Universidade Estadual da Paraíba, Brasil \\ E-mail: lucasmorais7@gmail.com \\ Eunice Ferreira Carvalho \\ ORCID: https://orcid.org/0000-0002-2333-1342 \\ Universidade Estadual da Paraíba, Brasil \\ E-mail: elocarvalho12@gmail.com \\ Cinthia Moura Frade \\ ORCID: https://orcid.org/0000-0002-2826-816X \\ Universidade Estadual da Paraíba, Brasil \\ E-mail: admcinthiafrade@gmail.com \\ Geymeesson Brito da Silva \\ ORCID: https://orcid.org/0000-0001-5645-7067 \\ Universidade Federal de Pernambuco, Brasil \\ E-mail: geimerson57@gmail.com \\ Cícero Otávio de Lima Paiva \\ ORCID: https://orcid.org/0000-0003-3740-4191 \\ Universidade Estadual do Rio Grande do Norte, Brasil \\ E-mail: cicero.otavio@ hotmail.com \\ Ronyelsom dos Santos Martins \\ ORCID: https://orcid.org/0000-0002-9922-6557 \\ Universidade Estadual da Paraíba, Brasil \\ E-mail: ronyelsonmartins@outlook.com \\ Francieude Oliveira de Souza \\ ORCID: https://orcid.org/0000-0002-2960-1788 \\ Universidade Estadual da Paraíba, Brasil \\ E-mail: eudessouza678@gmail.com \\ Jamily Neves de Lima \\ ORCID: https://orcid.org/0000-0001-9968-4358 \\ Universidade Estadual da Paraíba, Brasil \\ E-mail: nevesjamily27@gmail.com \\ Antonio Augusto Martins dos Santos \\ ORCID: https://orcid.org/0000-0003-0417-1176 \\ Universidade Estadual da Paraíba, Brasil \\ E-mail: antoniomsipb@gmail.com
}

\begin{abstract}
Resumo
O estudo teve como objetivo identificar a configuração jurídico-institucional e o processo decisório na gestão das Instituições Participativas ou Deliberativas Ambientais no território da cidadania do Médio Sertão-PB, buscando apontar ações da gestão participativa em/nas tomadas de decisões ambientais sustentáveis. Para responder ao objetivo nesta pesquisa, utilizou-se do método qualitativo, além da pesquisa descritiva, documental e de campo. Como resultado, observou-se que os conselhos analisados detêm grande parte de sua funcionalidade focada no
\end{abstract}


desenvolvimento do Programa, havendo pouca ocorrência de falas relacionadas aos impactos na agricultura, cadeia produtiva e sustentabilidade. Podendo sua existência, em maior quantidade de municípios, estar atrelada à questões financeiras (repasse e fiscalização de repasse de recursos), o que diferencia dos Conselhos de temática ambiental, os quais possuem pouca presença dos municípios do território, por não tratar diretamente com políticas públicas que possuam repasses financeiros ou pelo fato da implementação de políticas públicas não estarem atreladas a sua existência. Dentre as questões relacionadas ao processo decisório pode-se destacar que a maior parte das decisões são assuntos relacionados às questões administrativas e burocráticas que dizem respeito à própria gestão pública.

Palavras-chave: Gestão participativa; Meio ambiente; Território; Conselhos.

\begin{abstract}
The study aimed to identify the legal-institutional configuration and the decision-making process in the management of Participatory or Environmental Deliberative Institutions in the territory of the citizenship of the Middle Sertão-PB, seeking to point out participatory management actions in / in making sustainable environmental decisions. To answer the objective in this research, we used the qualitative method, in addition to descriptive, documentary and field research. As a result, it was observed that the councils analyzed have a large part of their functionality focused on the development of the Program, with little occurrence of speeches related to the impacts on agriculture, the production chain and sustainability. Its existence, in a greater number of municipalities, may be linked to financial issues (transfer and inspection of transfer of resources), which differs from Councils with an environmental theme, which have little presence of municipalities in the territory, as they do not deal directly with policies that have financial transfers or because the implementation of public policies is not linked to their existence. Among the issues related to the decision-making process, it can be highlighted that most decisions are related to administrative and bureaucratic issues that concern public management itself.
\end{abstract}

Keywords: Participative management. Environment. Territory. Advices.

\title{
Resumen
}

El estudio tuvo como objetivo identificar la configuración jurídico-institucional y el proceso de toma de decisiones en la gestión de Instituciones Ambientales Participativas o Deliberativas en el territorio de ciudadanía del Médio SertãoPB, buscando señalar acciones de gestión participativa en / en la decisión ambiental sostenible. -haciendo. Para dar respuesta al objetivo de esta investigación se utilizó el método cualitativo, además de la investigación descriptiva, documental y de campo. Como resultado, se observó que los concejos analizados tienen gran parte de su funcionalidad enfocada al desarrollo del Programa, con poca ocurrencia de discursos relacionados con los impactos en la agricultura, la cadena productiva y la sostenibilidad. Su existencia, en un mayor número de municipios, puede estar ligada a cuestiones económicas (traspaso e inspección de traspaso de recursos), lo cual se diferencia de los Ayuntamientos con temática ambiental, que tienen poca presencia de municipios en el territorio, por no atender directamente con políticas que tienen transferencias financieras o porque la implementación de políticas públicas no está ligada a su existencia. Entre los temas relacionados con el proceso de toma de decisiones, se puede destacar que la mayoría de las decisiones son asuntos relacionados con temas administrativos y burocráticos que conciernen a la propia administración pública.

Palabras clave: Gestión participativa; Medio ambiente; Territorio; Consejos.

\section{Introdução}

A relação da sociedade com o meio ambiente é marcada pela imposição de padrões de consumo, exploração e degradação dos recursos naturais, afetando assim, a qualidade de vida e o bem-estar. Além disso, é possível observar que as constantes degradações e violações dos recursos ambientais têm entre suas causalidades as transformações econômicas e políticas “exigidas” pelas sociedades pós-modernas.

Frente ao exposto, a busca pelo ambiente ecologicamente equilibrado passou a ser objetivo central das nações para transformar o mundo (Objetivos de Desenvolvimento Sustentável da ONU). O Brasil, por sua vez, constitucionalizou o meio ambiente como direito fundamental (art. 225 da CF/88) e a titularidade desse direito pertence a todos (a presente e as futuras gerações) por ser o meio ambiente um bem de uso comum, estabelecendo a participação conjunta entre os entes federados e a coletividade na proteção dos recursos ambientais, sagrando, deste modo, o princípio da participação como a essência de uma gestão democrática.

Nesse sentido, a gestão participativa-democrática, enquanto ideário teórico, pressupõe a existência de soberania e participação dos cidadãos nos processos de tomadas das decisões da e na administração pública, seja de forma direta, seja por meio de representação. O próprio conceito de democracia está intimamente ligado à constituição de cidadania, do 
empoderamento e da transformação social (Manzini-Covre, 2002), ao configurar sua existência à prática de reivindicação e de apropriação de espaços públicos, em que sejam assegurados aos indivíduos o respeito e a busca pela efetivação de direitos fundamentais, não abrigando qualquer privação ou violação.

A participação popular efetiva constituiu uma condição necessária para a existência de uma democracia (Bobbio, 2000; Dahl, 2001), principalmente quando se trata decisões sobre bens públicos (bens ambientais), pois se configuram como problemas de ação coletiva, exigindo compromisso com outras pessoas (responsabilidade ética e moral), não sendo, assim, concebível a tomada de decisão de forma individual, dada a natureza do meio ambiente.

Diante da atual crise ambiental, cuja a responsabilidade da tutela ecológica para as presentes e futuras gerações é do Estado e da sociedade, possibilitando ao último o exercício da cidadania ao torna-se parte do processo de tomada de decisão, faz-se então necessário o estabelecimento de canais e espaços de participação popular, visando a concretização de uma gestão participativa, preconizando a garantia da cidadania, através do poder exercido pela sociedade sobre a Administração Pública ao influenciar, observar, controlar e participar das formulações e execuções de políticas públicas sociais e ambientais, de forma compartilhada entre atores sociais, institucionais e organizações públicas e privadas.

Entretanto, apesar das Instituições Deliberativas se configurarem como espaços participativos, ainda restam dúvidas quanto à efetividade desse mecanismo na construção de políticas sociais, ambientais e econômicas democráticas, especialmente em relação à sua existência e a capacidade dos atores de influenciarem nas tomadas de decisões ambientais.

Tais reflexões derivaram, portanto, o seguinte problema: Qual a estruturação jurídica-institucional da gestão participativa nas tomadas de decisões ambientais no território da cidadania do Médio Sertão-PB? Para tanto, o presente trabalho tem como objetivo identificar a configuração jurídico-institucional e do processo decisório na gestão das Instituições Deliberativas ambientais no território do Médio Sertão-PB.

A escolha do Território Médio Sertão-PB se explica em função das suas diferentes características físicas, econômicas, ambientais e de identidade sociocultural. No que se refere às motivações ambientais, ocorre por apresentar uma diversificação de recursos naturais e também de problemas e impactos ambientais causados pelas ações antrópicas e variações climáticas que tem desencadeado um processo de desertificação, degradação (das zonas semiáridas), secas e injustiças ambientais. Pelas motivações sociopolíticas, tendo em vista que o Centro de Ciências Exatas e Sociais Aplicadas (CCEA), Campus VII, da Universidade Estadual da Paraíba (UEPB) sendo localizado no município de Patos-PB, que compõe o Território Médio Sertão e pelo Grupo de Estudos e Pesquisas em Administração Socioambiental (GEPAS), do curso de Bacharelado em Administração, tendo dentro de suas perspectivas de estudos, pesquisas envolvem a gestão, participação e educação no processo de formulação de políticas sociais e ambientais, ver-se a necessidade de produzir pesquisas sobre/para/no território do Médio Sertão.

\section{Referencial Teórico}

\subsection{Instituições Participativas ou Deliberativas, Gestão Participativa e Conselhos Ambientais}

No Brasil, como um Estado Democrático de Direito, o poder é emanado do povo, sendo exercido pelos representantes eleitos ou diretamente, conforme previsão constitucional (art. 1 ${ }^{\circ}$, caput e parágrafo único, CRFB/88). Gohn (2004, p. 22) explica que, no período pós promulgação da constituição, a cidadania passou a ser discutida oficialmente e vivenciou um processo de ressignificação, aproximando-se da "[...] ideia de participação civil, de exercício da civilidade, de responsabilidade social dos cidadãos como um todo", pois, ainda conforme a autora, a cidadania além de tratar os direitos, também compreende os deveres, na busca pela responsabilidade dos cidadãos em áreas públicas, por meio de parcerias no contexto das políticas sociais governamentais. 
É importante destacar que a Constituição de 1988 foi promulgada num contexto de fim de período ditatorial, no qual a participação das pessoas no debate político e manifestação da liberdade de opinião eram tolhidos pela força opressora do Estado. Com a redemocratização e a busca pela participação da sociedade na construção de políticas ambientais observamos uma retomada dos primeiros debates acerca das questões ambientais "em que os movimentos sociais desempenharam papel fundamental na criação e consolidação de um pensamento crítico acerca da crise ambiental agravada pela expansão do sistema capitalista" (PAIVA, 2020, p. 52).

As Instituições Participativas ou Deliberativas (IPs) (Tatagiba, 2002; Avritzer, 2009) surgem como um dos instrumentos que asseguram o processo de tomada de decisão em defesa do meio ambiente e uma forma de se pensar na democracia ambiental, pela possibilidade que esses arranjos, teoricamente, proporcionam discussões, diálogo e debates públicos para formação de uma decisão coletiva em favor dos recursos comuns.

Instituições deliberativas, embora não garantam uma avaliação dos bens ambientais enquanto bens públicos, tornam mais provável que esse tipo de avaliação estabeleça-se. Isto porque, em tais instituições, pressupõe-se que os argumentos devam ser colocados em termos do bem comum e não do bem-estar individual. Eles são avaliados, levando-se em consideração a comunidade ou a sociedade num sentido mais geral, e não os benefícios associados a um indivíduo ou grupo em particular. Nessas instituições, os participantes também são obrigados a considerar vários pontos de vista sobre um problema, o que pode fazê-los rever o seu posicionamento inicial. Isso sugere que tais instituições não buscam revelar as preferências das pessoas em relação ao meio ambiente, o que abordagens econômicas buscam fazer, mas possuem um papel de construir tais preferências. Finalmente, instituições deliberativas podem estimular o reconhecimento das ligações existentes entre os participantes do processo político, bem como influenciar na criação de uma maior solidariedade entre eles (Lenzi, 2009, p. 24).

Por isso, Sen (2010) ressalta a importância de existência de discussões e debates públicos, pois é por meio de arenas, espaços e instituições participativas que proporcionem a participação e do diálogo público, quando bem fundamentadas e menos marginalizadas, podem influenciar positivamente as questões ambientais, sociais e fortalecer o funcionamento do sistema democrático.

Assim, o essencial na gestão participativa ambiental é conceder maior espaço para atuação da sociedade civil, com liberdade para se discutir e manter o diálogo em prol da mudança ambiental, dando um critério objetivo a essa participação com o intuito de abolir com as vontades privadas dos administradores (governantes) e interesses do capital (econômico), como forma de diminuir os parâmetros clientelistas que perduram na política brasileira e marginaliza os interesses e valores de movimentos e grupos ambientais (Avritzer, 2009; Giaretta, Fernandes \& Philippi-Jr, 2012).

No entanto, mesmo que seja algo desejável, a gestão participativa ambiental ainda encontra muitos óbices a serem superados, fruto do pensamento determinado pelo "homo economicus do século XXI" (DOWBOR, 2012, p. 8), em que o modelo de consumo dos recursos naturais é o dos ricos, assim, o meio ambiente por vezes se torna um objeto maculado frente aos interesses econômicos, ainda que seja discutido no âmbito de outros poderes (ex. legislativo e judiciário), gerando, assim, a crise socioambiental, decorrente da distância entre aquilo que foi planejado e o que vem sendo efetivamente alcançado (Bordignon \& Gracindo, 2006; Castro, 2009).

No contexto brasileiro, a participação social apresenta duas vertentes: participação institucionalizada e a não institucionalizada. A participação institucionalizada refere-se à atuação de entidade e órgãos, como as categorias sindicais, dos conselhos (saúde, educação, meio ambiente, entre outros) e outras Instituições Participativas (IPs). A participação não institucionalizada acontece através dos movimentos sociais, sem categorização como entidade ou órgão (Avritzer, 2016).

Considerando a participação institucionalizada, os conselhos gestores são importantes meios da execução dessa forma, existindo em níveis nacionais, estaduais e municipais, além de atuarem com o objetivo de aperfeiçoar as políticas públicas no país. Em nível local "os conselhos consagram-se como o instituto de participação popular mais atuante na esfera Executiva brasileira, exercendo atividades importantes na definição às políticas públicas municipais” (Santin \& Pandolfo, 2016, p. 212). 
Corroborando as ideias apresentadas, é importante salientar que o processo consultivo dos conselhos, numa perspectiva de pensamento educativo e de exercício de cidadania, é essencial para que haja o efetivo funcionamento do espaço público, contexto em que são fomentadas as intencionalidades, debates e disputas dos agentes sociais participantes neste processo (Loureiro \& Cunha, 2008).

Direcionado a temática ambiental, a participação em Conselhos Ambientais deve ser garantida para que seja atendido o preceito constitucional sobre a defesa do meio ambiente por parte da sociedade civil e do poder público (Morais, 2017; Morais et al., 2021). Nesse sentido, Cabral Neto e Macedo Filho (2010, p. 45) refletem que "a efetiva proteção do meio ambiente está associada ao desenvolvimento de ações que tenham como requisito a plena participação do coletivo social, remetendo à necessária consolidação de uma sociedade democrática e participativa".

Deste modo, os Conselhos Ambientais são considerados instâncias que visam promover a cidadania e a participação, como uma obrigação para a construção da política ambiental (Facin, et. al., 2012), cuja participação ocorre voluntariamente, compostos por membros representantes do poder público, de entidades e da sociedade civil. Estes desempenham a função de gerenciador de recursos relativos a ações ambientais, coordenar ações locais, conscientização da população sobre o meio ambiente dentre outras atividades (Morais, 2017; Santos \& Paes, 2020).

No âmbito ambiental local, conforme Souza e Novicki (2011), os Conselhos temáticos relacionados a proteção e defesa do meio ambiente, denominados de Conselhos Municipais de Meio Ambiente (CMMA), possuem valor, pois podem demonstrar a possibilidade de determinado município ter condições de criar, regulamentar e implantar suas políticas públicas sociais, inclusive no âmbito do meio ambiente.

Os CMMA são, portanto, considerados instrumentos importantes para possibilitar a participação da sociedade no exercício da gestão ambiental local (Ferreira \& Fonseca, 2014), e consequentemente, uma forma de se colocar em prática a democracia local, apesar de existirem discussões que demonstram limites na participação da comunidade nesses conselhos (Souza \& Novicki, 2011).

Além dos CMMA, é possível inserir o Conselho de Desenvolvimento Rural Sustentável, que discute temáticas ambientais focadas no território rural, por isso é considerada sua importância no território em que a pesquisa foi realizada. O Conselho Nacional de Desenvolvimento Rural Sustentável (CNDRS) se constitui das diretrizes, objetivos e metas dos programas nacionais de reforma agrária, do fortalecimento da agricultura familiar e da geração de renda do setor rural (Brasil, 2000). Além de coordenar, articular e propor a adequação das políticas públicas federais às necessidades de desenvolvimento rural sustentável, cumprimento os objetivos e as metas dos programas de fortalecimento da agricultura familiar. Segundo Marques e Flexor (2008), o CNDRS possui sua estruturação interligada com a implantação do Programa Nacional de Fortalecimento da Agricultura Familiar (PRONAF), que mostrou novas bases para elaboração das políticas públicas de Desenvolvimento Rural.

O Ministério do Meio Ambiente relata que o modelo do Desenvolvimento Rural no Brasil tem passado por uma transição, que consiste no desafio de superar a dicotomia entre produção e proteção ambiental, por meio dos instrumentos de políticas ambientais e agrícolas dentro do desenvolvimento sustentável. Em geral, a transição para a sustentabilidade do rural objetiva assegurar o crescimento econômico, reduzir as desigualdades sociais, conservar os recursos naturais e a capacidade produtiva dos ecossistemas, e ainda busca reverter o estágio atual de degradação causado pela agropecuária.

O Desenvolvimento Rural Sustentável tem, portanto, a finalidade de incentivar o uso adequado da terra e dos recursos naturais, seja nas áreas de agricultura familiar, assentamentos da reforma agrária, Terras Indígenas, seja em Comunidades Extrativistas, Áreas Susceptíveis à Desertificação (ASD) e áreas de produção agropecuária de tipo patronal/empresarial de grande escala (MMA, 2020). 


\section{Metodologia}

O presente estudo utilizou em sua abordagem o método qualitativo (Vergara, 2016), tendo em vista que buscou descrever, compreender e explicar o contexto do problema de pesquisa, a fim de tornar possível demonstrar como a estruturação das instituições deliberativas fortalece a gestão participativa nas tomadas de decisões ambientais no território da cidadania do Médio Sertão-PB. Para tanto, a classificação metodológica deste estudo partiu da taxionomia utilizada por Vergara (2016), nos aspectos: quanto aos fins, consistindo em uma pesquisa descritiva; quanto aos meios, caracterizada como pesquisa documental e de campo.

Classificou-se como pesquisa descritiva, pois buscou a representação de características de uma população, de um fenômeno ou de estabelecer relação entre variáveis (Gil, 2008). Denomina-se, ainda, como pesquisa documental, por se valer em sua análise de documentos das próprias instituições participativas, beneficiando-se de atas de reuniões, relatórios, documentos oficiais, registros e legislações.

Além disso, a pesquisa também é considerada um estudo de campo, pela investigação e coleta de dados (Creswell, 2010), no qual se valeu de requerimentos realizados através do portal de sistema de informação ao cidadão (SIC), assim como as visitas feitas nas prefeituras municipais, nas devidas secretarias e órgãos competentes.

Para realização do estudo de campo, foi entrado em contato com todos os municípios, pelos telefones disponíveis nas páginas, e/ou pelo SIC (por meio de solicitações direcionadas as prefeituras de cada município), e ainda com acesso a legislação municipal, através dos portais das prefeituras e da câmara municipal das cidades que disponibilizam essas informações. Vale destacar que, em alguns municípios, as solicitações não foram atendidas, considerando que os pedidos de informações foram feitos no segundo semestre do ano de 2019, no entanto, não se obteve resposta sobre a possível existência e a situação atual dos conselhos, através dos meios de comunicação utilizados e citados anteriormente.

\subsection{Local de pesquisa}

A pesquisa foi realizada nos municípios do Território do Médio Sertão do Estado da Paraíba (Figura 1), que está situado na região Nordeste do país, este possui uma área total de $6037.7000 \mathrm{~km}^{2}$, composto por 24 municípios (Areia de Baraúnas, Cacimba de Areia, Cacimbas, Catingueira, Condado, Desterro, Imaculada, Junco do Seridó, Mãe d’Água, Malta, Matureia, Passagem, Patos, Quixaba, Salgadinho, Santa Luzia, Santa Teresinha, São José de Espinharas, São José do Bonfim, São José do Sabugi, São Mamede, Teixeira, Várzea, Vista Serrana). A população total desse território é de 232.585 habitantes, com população urbana de 176.878 habitantes (76,05\%) e rural de 55.707 habitantes (23.95\%) (MDA, SIT, 2019). 
Figura 1 - Território do Médio Sertão-PB.

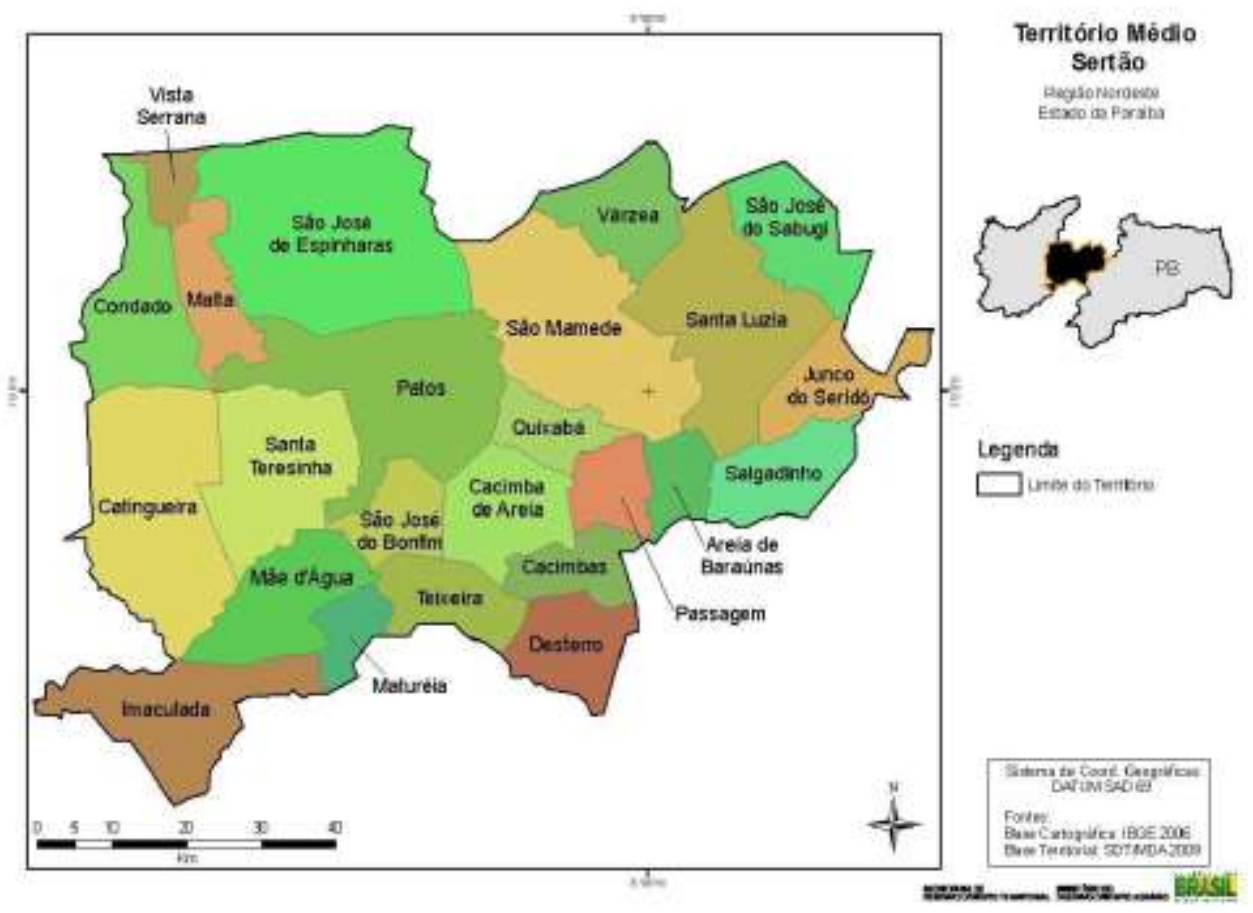

Fonte: MDA, SIT (2020).

Nessa região predomina a vegetação da caatinga, embora existam outras formações florestais, no passado essa área era coberta por uma mata de alto porte, dominada por baraúnas, aroeiras, pereiros e catingueiras. Com relação ao clima, possui médias de temperaturas elevadas e precipitações médias anuais inferiores a $800 \mathrm{~mm}$, causando períodos de chuvas e estiagens.

O território conta com algumas áreas de preservação: A fazenda Tamanduá que é uma Reserva Particular do Patrimônio Natural (RPPN), localizada no município de Santa Terezinha; o Parque do Pico do Jabre (unidade de conservação) no município de Matureia com 851 km de extensão e o Pico de Jabre, ponto de relevo mais alto da Paraíba, com $1.197 \mathrm{~m}$ de altitude, situado no município de Matureia (MDA, SIT, 2020).

Outro atrativo nessa região é o desenvolvimento de energias renováveis, onde estão sendo instalados complexos de energia eólica e solar. De acordo com o grupo Iberdrola, o Complexo Eólico da Paraíba, entrará em funcionamento entre 2022 e 2023, com uma capacidade instalada de mais de 565MW, está localizado próximo ao município de Santa Luzia, que é considerado uma das áreas mais ventosas da América; e o Complexo Fotovoltaico Angico e Malta, localizado no município de Malta, possui cerca de 195.000 módulos fotovoltaicos e 63.13 MWp instalados (WEG, 2019; Nascimento et al., 2020).

\subsection{Pesquisa documental}

A investigação documental trabalha com documentação interior de órgãos públicos e privados de qualquer natureza, como também com pessoas através de registros, anais, regulamentos, ofícios, comunicações informais, fotografias, cartas dentre outros tipos de informações (Vergara, 2016), sendo possível, a partir da mesma, analisar a participação do ponto de legal e formal, através dos documentos das próprias instituições participativas, bem como verificar seu funcionamento e as atividades desenvolvidas pelos conselhos. Classificou-se dessa forma, pois se valeu de atas de reuniões, regimento interno, relatórios, diagnósticos, regulamentos, leis, projetos de lei, resoluções, dentre outros documentos, que estão à disposição para o acesso público.

O acesso às atas de reuniões ocorreu de dois modos: a) Como respostas das prefeituras e/ou das devidas secretarias, as solicitações feitas pelo portal de sistema de informação ao cidadão; b) Por meio do contato direto dos pesquisadores com os 
órgãos competentes. Desse modo, para obtenção das informações, foram lidas e analisadas todas as atas de reuniões ordinárias, especificamente dos anos de 2017, 2018 e 2019, as quais foram essenciais para o entendimento dos assuntos abordados pelos conselhos.

O tratamento e a análise dos dados ocorreram por meio do Programa Excel (Microsoft Corp., EUA), sendo demonstrados através de dados gráficos e tabelas (numéricos e/ou percentuais), criação de mapas no software AutoCAD e na operacionalização da análise qualitativa com os princípios básicos da Análise de Conteúdo (Bardin, 2016).

\section{Resultados e Discussão}

A partir da década de 1970, tem sido possível acompanhar um aumento na preocupação com questões inseridas no eixo ambiental, incluindo "[...] na agenda das administrações públicas e privadas a necessidade de uma gestão ambiental eficaz com foco no desenvolvimento sustentável [...] para conferir legitimidade à política de meio ambiente" (Ferreira \& Fonseca, 2014, p. 239).

O arranjo jurídico-institucional dos Conselhos deliberativos focados no meio ambiente em nível municipal (Conselhos de Desenvolvimento Rural Sustentável e Conselhos de Meio Ambiente) da região do Território do Médio Sertão (PB) pode ser visualizado na Figura 2. Nesse mapa do território, a cor laranja refere-se a existência de CMMA e a verde de CMDRS, a cor vermelha refere-se aos inexistentes (municípios que não possuem nenhum dos dois conselhos legalmente instituídos), e a cor azul destaca os municípios "sem informações", ou seja, que não se obteve informação através dos portais de acesso. Vale salientar que os municípios estabelecidos no mapa com mais de uma cor, demonstram que estes possuem mais de um conselho.

É importante pontuar que a dificuldade de acesso a informações nos portais de alguns municípios, em virtude de não terem sido disponibilizadas, fere diretrizes básicas discutidas na Lei 12.527/2011 que regula e busca assegurar o acesso à informação. Duas dessas diretrizes merecem destaque: divulgação de informações de interesse público, independentemente de solicitações e utilização de meios de comunicação viabilizados pela tecnologia da informação (Brasil, 2011). 
Figura 2 - Mapa dos Conselhos existentes no Território do Médio Sertão-PB.

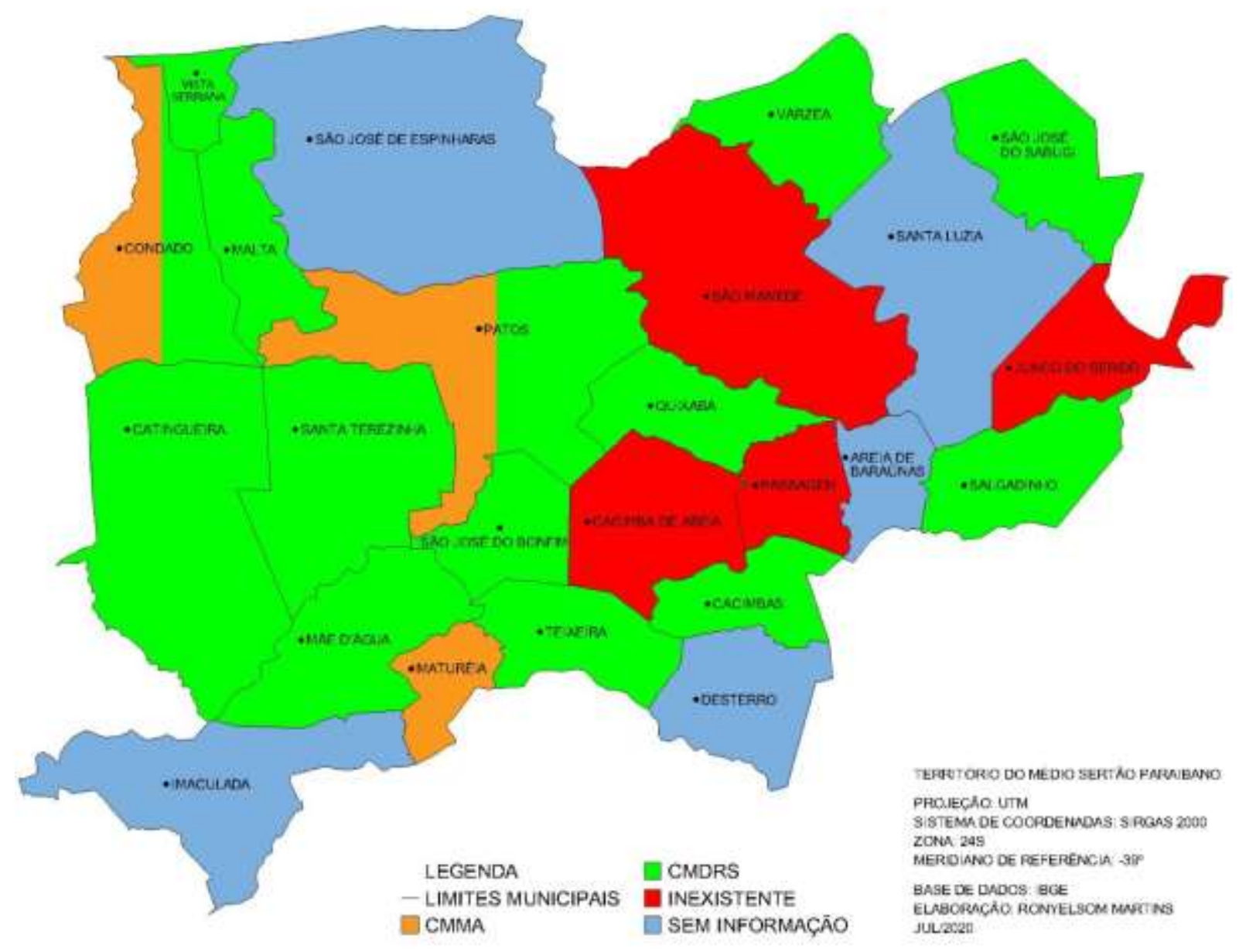

Fonte: Autores (2020).

Nesta pesquisa, os Conselhos com foco ambiental foram classificados em quatro situações: ativos, inativos e inexistentes, sem informações. Foram considerados: 1) ativo, os conselhos instituídos formalmente e que esteja em funcionamento tendo realizado reuniões entre os anos de 2017 a 2019; 2) inativos, os conselhos que foram instituídos perante a lei, porém não está em atividade neste período; c) inexistente, condição dos municípios que não possuem norma legal instituindo Conselho Ambiental e/ou conselho de Desenvolvimento Rural sustentável; d) sem informações os municípios em que não foi possível o acesso das informações na coleta de dados. O Quadro 1 demonstra a sistematização dessas informações: 
Quadro 1 - Situação dos Conselhos de temática ambiental no território do Médio Sertão-PB.

\begin{tabular}{|c|c|c|}
\hline MUNICÍPIOS & $\begin{array}{c}\text { CONSELHO MUNICIPAL DE } \\
\text { MEIO AMBIENTE }\end{array}$ & $\begin{array}{l}\text { CONSELHO MUNICIPAL DE } \\
\text { DESENVOLVIMENTO RURAL } \\
\text { SUSTENTÁVEL }\end{array}$ \\
\hline Areia de Baraúnas & Sem informações & Sem informações \\
\hline Cacimba de Areia & Inexistente & Inexistente \\
\hline Cacimbas & Inexistente & Inativo \\
\hline Catingueira & Inexistente & Inativo \\
\hline Condado & Inativo & Ativo \\
\hline Desterro & Sem informações & Sem informações \\
\hline Imaculada & Sem informações & Sem informações \\
\hline Junco do Seridó & Inexistente & Inexistente \\
\hline Mãe d'Água & Inexistente & Ativo \\
\hline Malta & Inexistente & Inativo \\
\hline Matureia & Inativo & Inexistente \\
\hline Passagem & Inexistente & Inexistente \\
\hline Patos & Ativo & Ativo \\
\hline Quixaba & Inexistente & Inativo \\
\hline Salgadinho & Inexistente & Inativo \\
\hline Santa Luzia & Sem informações & Sem informações \\
\hline Santa Terezinha & Inexistente & Inativo \\
\hline São José das Espinharas & Sem informações & Sem informações \\
\hline São José do Bonfim & Inexistente & Inativo \\
\hline São José do Sabugi & Inexistente & Ativo \\
\hline São Mamede & Inexistente & Inexistente \\
\hline Teixeira & Inexistente & Inativo \\
\hline Várzea & Inexistente & Ativo \\
\hline Vista Serrana & Inexistente & Ativo \\
\hline
\end{tabular}

Fonte: Autores (2020).

Com base no Quadro anterior, observa-se que 15 municípios do território do Médio Sertão Paraibano dispõem de uma estrutura organizacional ligada à área ambiental em sua legislação, no entanto, não são todos os conselhos que estão em funcionamento, no quadro estes classificam-se como inativos.

Os municípios que estão descritos como "sem informações", são assim denominados porque foram solicitadas informações por diversos meios existentes como: Sites das prefeituras e das câmaras, cujas páginas não registravam ou continham informações sobre IPs, quando ocorria isso era tentado comunicação diretamente com os órgãos públicos municipais por telefones e correio eletrônico, e sem retorno ou impossibilidade por esses meios de comunicação, era requerido junto ao Serviço de Informação ao Cidadão (SIC) que prestassem informações sobre os IPs, de forma que ao não obter-se resposta do SIC, esses municípios foram classificados dessa maneira. O Gráfico 1 detalha percentualmente as informações contidas no Quadro 1. 
Research, Society and Development, v. 10, n. 7, e43510716639, 2021

(CC BY 4.0) | ISSN 2525-3409 | DOI: http://dx.doi.org/10.33448/rsd-v10i7.16639

Gráfico 1 - Comparativo situacional das IPs (CMMA x CMDRS).

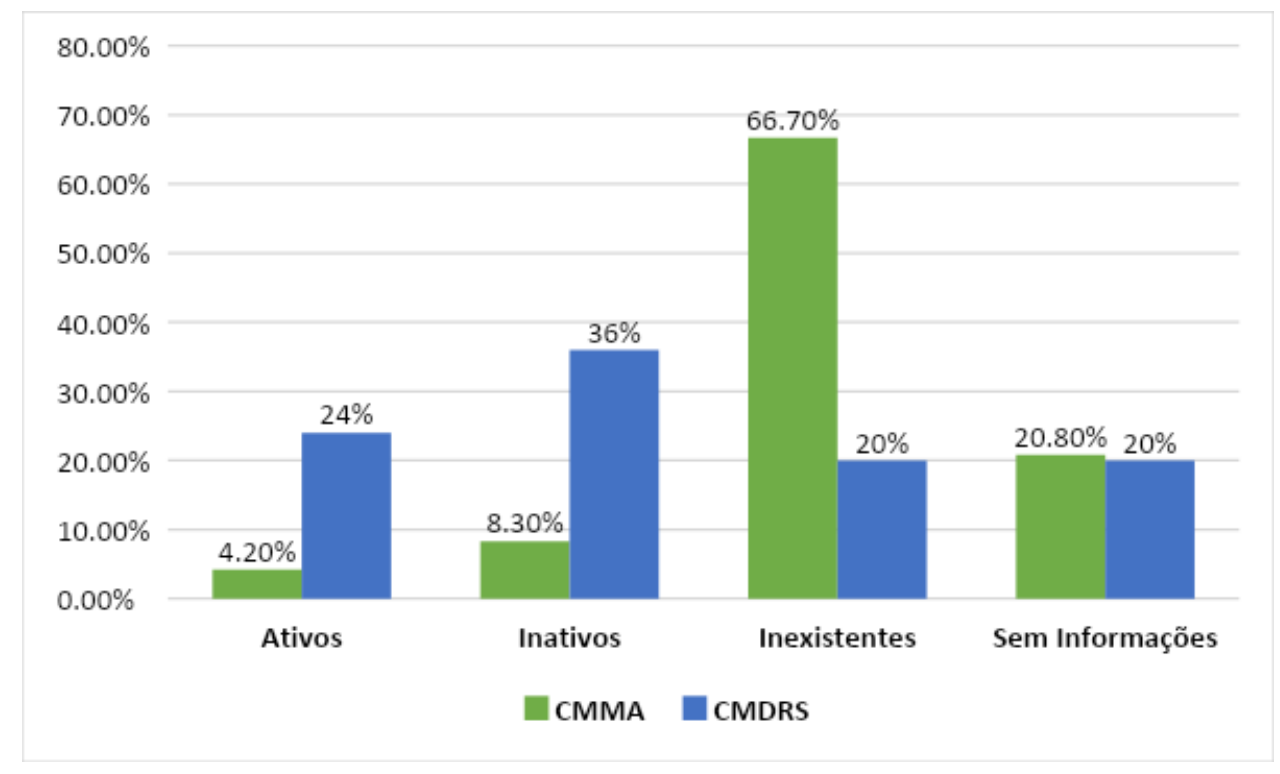

Fonte: Autores (2020).

Dentre os municípios do território do Médio Sertão, três Conselhos de meio ambiente estão instituídos legalmente, no entanto apenas um se encontra ativo. Desse modo classificam-se como ativos 4,2\%, inativos 8,3\%, inexistentes 66,7\% e 20,8\% denominam-se sem informações, totalizando assim, os conselhos dos 24 municípios pesquisados.

Os Conselhos de desenvolvimento rural sustentável, se encontram ativos $24 \%$, inativos $36 \%$, inexistentes $20 \%$ e $20 \%$ não foram encontradas informações a respeito da legislação ambiental e da atual situação dos órgãos, que foram os municípios de Areia de Baraúnas, Desterro, Imaculada, Santa Luzia, São José das Espinharas.

Assim, na dimensão institucional-legal é possível perceber que os municípios que tiveram conselhos ativos e inativos, e a sua criação nas normas jurídicas, como mostra o Quadro 2. 
Quadro 2 - Norma legal.

\begin{tabular}{|c|c|c|}
\hline Municípios & $\begin{array}{c}\text { Conselho Municipal de Meio } \\
\text { Ambiente }\end{array}$ & $\begin{array}{c}\text { Conselho Municipal de } \\
\text { Desenvolvimento Rural Sustentável }\end{array}$ \\
\hline Areia de Baraúnas & - & - \\
\hline Cacimba de Areia & - & - \\
\hline Cacimbas & - & Lei Municipal No 08/1998 \\
\hline Catingueira & - & Lei Municipal No $532 / 2012$ \\
\hline Condado & Lei Municipal No 386/2013 & $\begin{array}{c}\text { Lei Municipal } \mathrm{N}^{\circ} 181 / 97 \text { Reformulado } \\
\text { pela Lei } \mathrm{N}^{\circ} 377 / 98\end{array}$ \\
\hline Desterro & - & - \\
\hline Imaculada & - & - \\
\hline Junco do Seridó & - & - \\
\hline Mãe d'Água & - & $\begin{array}{c}\text { Lei Municipal } \mathrm{N}^{\circ} \text { 401/2012 } \\
\text { Reformulado pela Lei } \mathrm{N}^{\circ} 401 / 2012\end{array}$ \\
\hline Malta & - & Lei Municipal No 243/2012 \\
\hline Maturéia & Lei Municipal No $056 / 97$ & - \\
\hline Passagem & - & - \\
\hline Patos & Lei Municipal No $2.985 / 2000$ & Lei Municipal N³.778/2009 \\
\hline Quixaba & - & Lei Municipal No 303/2012 \\
\hline Salgadinho & - & $\begin{array}{c}\text { Lei Municipal } \mathrm{N}^{\circ} 052 / 2005- \\
\text { Reformulado pela Lei } N^{\circ} 079 / 2007\end{array}$ \\
\hline Santa Luzia & - & - \\
\hline Santa Terezinha & - & Lei Municipal No 397/2012 \\
\hline São José das Espinharas & - & - \\
\hline São José do Bonfim & - & Portaria $N^{\circ} 011 / 2019$ \\
\hline São José do Sabugi & - & $\begin{array}{c}\text { Lei Municipal No } 334 / 2001- \\
\text { Reformulado pela Lei No } 449 / 2011\end{array}$ \\
\hline São Mamede & - & - \\
\hline Teixeira & - & Lei Municipal No 197/2012 \\
\hline Várzea & - & $\begin{array}{c}\text { Lei Municipal } N^{\circ} 05 / 1998 \text { Reformulado } \\
\text { pela Lei } N^{\circ} 015 / 2011\end{array}$ \\
\hline Vista Serrana & - & Lei municipal $\mathrm{N}^{\circ} 011 / 2009$ \\
\hline
\end{tabular}

Fonte: Autores (2020).

No arranjo jurídico-institucional dos IPs do território, foi identificado 3 municípios com Conselhos de Meio Ambiente e 14 municípios com Conselho de Desenvolvimento Rural Sustentável com normativas jurídicas ou legislações municipais de regulamentação desses espaços. Para análise da configuração institucional das IPs, foram adotados os que estiveram em funcionamento durante o período compreendido entre 2017 e 2019, ou seja, do município de Patos, referente ao CMMA, e dos municípios de Condado, Mãe D’água, São José do Sabugi, Patos, Várzea e Vista Serrana, referentes ao CMDRS.

O Conselho Municipal de Meio Ambiente (CMMA) do Município de Patos-PB foi instituído pela Lei Municipal n 2.985/2000, sendo um "órgão de assessoramento do Poder Executivo e delibera sobre assuntos de sua competência, sobre as questões ambientais e demais Leis correlatas do Município" (artigo $1^{\circ}$ ). Este Conselho é composto pelos poderes públicos: Poder Executivo Municipal (representados por meio das secretarias: Agricultura e Meio Ambiente; Urbanismo e Obras Públicas; Serviços Públicos; Educação e Cultura; Saúde; Indústria e Comércio); pelos órgãos estaduais situados no município; e pelo Poder Legislativo Municipal. E ainda por membros da Sociedade Civil.

As reuniões ordinárias devem acontecer por convocação do presidente, ou pelo menos de $1 / 3$ de seus membros titulares (artigo $8^{\circ}$ ). Quanto ao tempo determinado entre uma e outra das reuniões ordinárias devem acontecer por periodicidade trimestral, tendo por quórum a maioria simples de seus conselheiros (artigo $\left.9^{\circ}\right)$. 
A análise do processo decisório, referente participação formal, as Atas de Reuniões do Conselho de Municipal de Meio Ambiente de Patos, correspondentes ao segundo semestre de 2017, compreendido nos meses de agosto, setembro, outubro e novembro, revelam que foram realizadas e registradas quatro reuniões ordinárias um em cada mês mencionado anteriormente. Os principais assuntos tratados nestas reuniões foram definidos como unidades de registro, à frente delas está a frequência em que são mencionadas, organizados em categorias como mostra a Tabela 1.

Tabela 1 - Atas de reuniões do CMMA.

\begin{tabular}{|c|c|c|}
\hline CATEGORIAS & UNIDADES DE REGISTROS & $\begin{array}{l}\mathrm{N}^{\circ} \text { DE OCORRÊNCIA } \\
\text { DAS PALAVRAS }\end{array}$ \\
\hline \multirow{7}{*}{$\begin{array}{l}\text { Gestão, Questões } \\
\text { administrativas e } \\
\text { burocracias }\end{array}$} & Licenças: LP, LI, LO & 14 \\
\hline & Licenciamento Ambiental & 10 \\
\hline & $\begin{array}{l}\text { Competências e Responsabilidade do } \\
\text { SUDEMA e SEMADS }\end{array}$ & 4 \\
\hline & Batalhão Ambiental & 4 \\
\hline & $\begin{array}{l}\text { Registro no Conselho Regional de } \\
\text { Engenharia e Agronomia (CREA) }\end{array}$ & 9 \\
\hline & Reversão de Multa & 5 \\
\hline & Posse dos conselheiros & 1 \\
\hline \multirow{8}{*}{$\begin{array}{l}\text { Resíduos Sólidos e } \\
\text { Saneamento Básico }\end{array}$} & Associação dos Catadores (ASPAC) & 9 \\
\hline & $\begin{array}{l}\text { Elaboração de Projetos de Construção de } \\
\text { filtros de fossas e sumidouro }\end{array}$ & 6 \\
\hline & Catadores do Lixão & 4 \\
\hline & Diagnóstico do Lixão & 4 \\
\hline & Coleta seletiva & 3 \\
\hline & Aterro Sanitário & 3 \\
\hline & Galpão da ASPAC & 2 \\
\hline & Fundo de Resíduos Sólidos & 1 \\
\hline \multirow{3}{*}{ Educação e Capacitação } & Criação Núcleo de Educação Ambiental & 2 \\
\hline & Núcleo de Educação Ambiental & 2 \\
\hline & Capacitação do MMA e SISNAMA & 2 \\
\hline Recursos Hídricos & Revitalização do Rio Espinharas & 2 \\
\hline
\end{tabular}

Fonte: Autores (2020).

Conforme foi possível observar, o Quadro 3 demonstra os assuntos em debates nas reuniões do Conselho, as quais foram organizados em quatro temas, classificados como categorias. Na primeira categoria: "gestão, questões administrativas e burocracias", estão presentes os assuntos mais comentados nessas atas de reuniões. Diante da função do conselho da emissão/autorização das licenças ambientais para empreendimentos municipais este item se destacou em todas as reuniões.

Na segunda categoria "Resíduos Sólidos e Saneamento Básico", em geral, os itens comentados estão relacionados ao lixão, demonstrando grande preocupação por parte dos conselheiros, discutiam acerca dos estudos levantados pelo SUDEMA com relação a situação do lixão de Patos, visando a construção de um aterro sanitário, e levantando formas de como as pessoas que sobrevivem da coleta e venda dos resíduos iriam obter sustento com a não existência do lixão. A associação dos catadores empregava apenas uma parte das pessoas que desempenham essa atividade de coleta e venda dos resíduos, pois não eram todos que tinham interesse de participação na ASPAC.

Já na terceira categoria "Educação e Capacitação", outro ponto enfatizado foi a criação de um núcleo de educação ambiental no município para que pudesse ser feito um trabalho maior de conscientização na população a partir da educação, todavia durante o ano de 2017 não foi concretizada a criação deste núcleo. Por fim, na quarta e última categoria "Recursos hídricos", a revitalização do Rio Espinharas foi um ponto comentado em duas reuniões do conselho, porém sem aprofundamento e discussão ampla, não sendo abordado subsídios para a sua efetiva realização. 
Observou-se que o conselho municipal de meio ambiente possui uma maior incidência de assuntos relacionados às questões administrativas e burocráticas, e aos resíduos sólidos, no entanto o primeiro é o que mais se destaca, podendo assim dizer que grande parte de sua função exercida pelo conselho está ligada a validação das normas da gestão pública.

Quando se trata dos Conselhos Municipais de Desenvolvimento Rural Sustentável, os municípios de Condado, Mãe D’água, Patos, São José do Sabugi, Várzea e Vista Serrana possuem em sua maioria uma estruturação semelhante, tanto na sua função enquanto órgão, como na composição dos membros dos conselhos. O Gráfico 2 mostra a classificação quanto o tipo de órgão.

Gráfico 2 - Classificação dos conselhos.

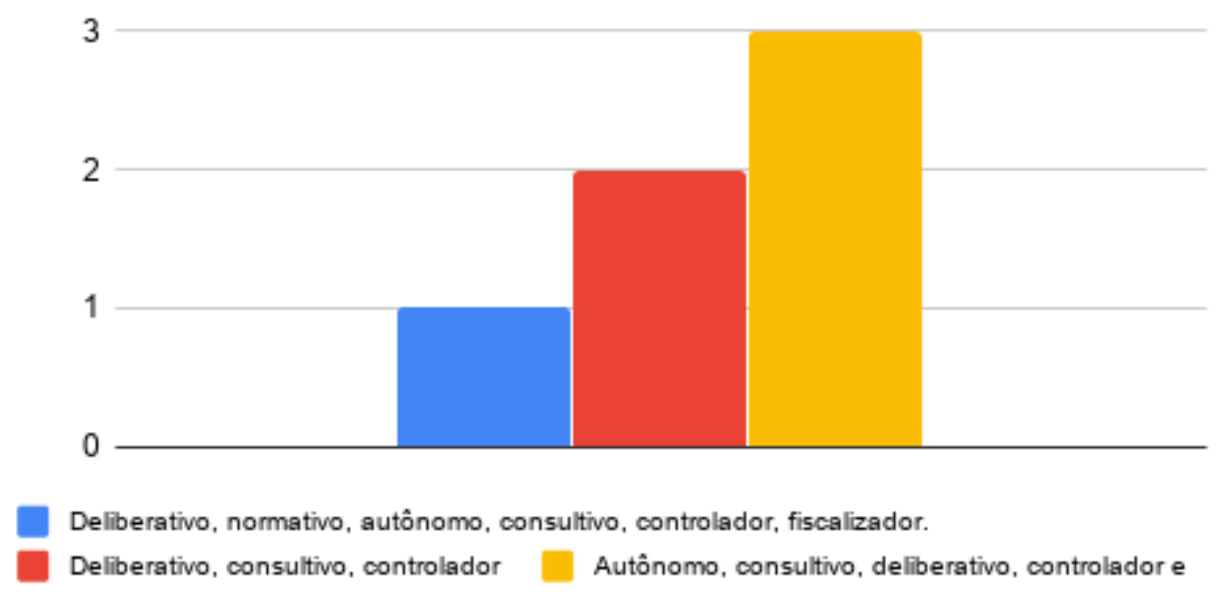

Fonte: Autores (2020).

O CMDRS do município de Condado possui pouca diferença entre os Conselhos de Patos, São José do Sabugi e Vista Serrana, pois além de ser um órgão autônomo, consultivo, deliberativo, controlador e fiscalizador, ele é também um órgão normativo, ou seja, possui poderes para instituições da atos normativos relacionados à temática do desenvolvimento rural sustentável. Já os Conselhos de Mãe D’água e Várzea são apenas deliberativos, consultivos, controladores.

Quanto à composição dos membros integrantes, os CMDRS são, geralmente, compostos por no máximo $50 \%$ de representantes dos poderes públicos e no mínimo $50 \%$ da sociedade civil. Dentre os municípios com CMDRS existente, cinco (Condado, Mãe d'água, São José do Sabugi, Várzea e Vista Serrana) possuem a composição exatamente iguais, definindo os representantes do poder público: Poder executivo; Poder Legislativo; Instituições Públicas. E os representantes da sociedade Civil: Instituições Religiosas; Sindicato dos Trabalhadores Rurais; e Representantes das associações comunitárias rurais; cooperativas e beneficiários das políticas públicas, programas e projetos municipais.

O CMDRS do município de Patos se diferencia por integrar um número maior de membros em sua composição, no entanto segue as mesmas indicações de máximo 50\% de representantes dos poderes públicos e no mínimo 50\% da sociedade civil. Compõem o conselho os poderes públicos: Poder executivo; Poder legislativo; EMATER local; EMBRAPA local; Secretarias Municipais (Saúde; Agricultura; Educação; Meio Ambiente e Assistência social); Instituição de ensino superior. Aqueles que representam a sociedade civil são: "Projeto COOPERAR"; associações rurais cadastrada no CMDRS; associações urbanas ligada ao CMDRS; Sindicato dos trabalhadores rurais; Sindicato rural de Patos; a FETAG; Instituições de crédito e fomento agrícola; e cooperativas.

Com relação ao processo decisório no CMDRS, dos seis municípios com conselhos ativos, obteve-se acesso às Atas de Reuniões de quatro municípios (Condado, São José do Sabugi, Várzea, Vista Serrana), totalizando 11 (onze) documentos, 
compreendido entre os períodos de 2017 a 2019, referente as reuniões realizadas nas IPs. Desse modo foram registrados os principais assuntos dessas reuniões ordinárias e organizados na Tabela 2.

Tabela 2 - Atas de Reuniões do CMDRS.

\begin{tabular}{|c|c|c|}
\hline CATEGORIAS & UNIDADES DE REGISTROS & $\begin{array}{c}\mathrm{N}^{\circ} \mathrm{DE} \\
\text { OCORRÊNCIA DAS } \\
\text { PALAVRAS }\end{array}$ \\
\hline \multirow{8}{*}{$\begin{array}{l}\text { Gestão, Questões } \\
\text { administrativas e } \\
\text { burocráticas }\end{array}$} & Calendário de Inscrição do Garantia Safra & 6 \\
\hline & Eleição & 5 \\
\hline & Formação de Chapas & 7 \\
\hline & Homologação das Inscrições do Programa & 12 \\
\hline & Inscrições do Programa Garantia Safra & 9 \\
\hline & $\begin{array}{l}\text { Proposta da DAP (Declaração de Aptidão ao } \\
\text { Pronaf) }\end{array}$ & 5 \\
\hline & Reestruturação do CMDRS & 1 \\
\hline & Votação & 5 \\
\hline \multirow{4}{*}{ Programas Sociais } & Programa Garantia de Sagra & 18 \\
\hline & Programas Sociais & 2 \\
\hline & Projetos sociais & 2 \\
\hline & Campanha de Vacinação Contra a Febre Aftosa & 2 \\
\hline \multirow[t]{2}{*}{ Meio ambiente } & Sustentabilidade & 1 \\
\hline & Parques Eólicos & 3 \\
\hline \multirow{5}{*}{ Agricultura } & Agricultores & 16 \\
\hline & Agricultoras & 4 \\
\hline & Cadeia Produtiva & 1 \\
\hline & Perdas da safra & 1 \\
\hline & Desenvolvimento Rural & 2 \\
\hline
\end{tabular}

Fonte: Autores (2020).

Diante os dados demonstrados no quadro observa-se 4 (quatro) categorias que facilitam os entendimentos as questões tratadas nos Conselhos Municipais de Desenvolvimento Rural Sustentável. Na primeira categoria, "Gestão, Questões administrativas e burocráticas", percebeu-se que a maior parte dos registros são referentes à homologação de inscrição, e elaboração de calendário do Programa Garantia Safra, e algumas ocorrências de fatores relacionados à gestão como as dos processos de eleições.

Na segunda categoria "Programas Sociais" destaca-se novamente o Programa Garantia Safra, com a maior em número de ocorrências registrado no quadro em análise, é muito superior em relação aos demais programas e projetos apresentados nas atas de reuniões. A terceira categoria, "Meio Ambiente", é a que menos tem destaque, já que apresenta um número reduzido de assuntos relacionados, demonstrando assim, uma importância mínima diante do conselho.

$\mathrm{Na}$ quarta categoria "Agricultura" foi possível evidenciar uma maior ocorrência que tratam de agricultores, em que mais uma vez está relacionada ao programa garantia safra, considerando que são os agricultores que têm seus nomes nas inscrições, homologação e demais fatores relacionados ao programa. Os outros itens desta categoria tiveram pouca relevância.

De tal maneira, verificou-se, por meio das atas de reuniões dos Conselhos, que os assuntos considerados de maior relevância foram os tratados nas categorias de gestão, questões administrativas e burocráticas; e programas sociais. Identificouse a maior incidência de assuntos atrelados ao programa de política pública de Garantia Safra, que é tratada nas duas categorias mencionadas acima.

Entende-se, dessa forma, que esses conselhos analisados detêm grande parte de sua funcionalidade focada no desenvolvimento do Programa, havendo pouca ocorrência de falas relacionadas aos impactos na agricultura, a cadeia produtiva, e da sustentabilidade. Além disso, a sua existência em maior quantidade de municípios, pode estar relacionada à 
questões financeiras (repasse e fiscalização de repasse de recursos), o que diferencia dos Conselhos de temática ambiental com pouca presença dos municípios do território, por não se tratar diretamente com políticas públicas que possuam repasses financeiros ou a implementação de políticas públicas estejam atreladas a sua existência.

\section{Conclusões}

O referido estudo buscou identificar a gestão participativa em/nas tomadas de decisões em instituições deliberativas ambientais do Território do Médio Sertão, a partir dos arranjos jurídicos-institucionais e do processo participativo nos Conselhos Municipais de Meio Ambiente (CMMA) e de Desenvolvimento Rural sustentável (CMDRS).

Dessa forma, evidenciou-se, a partir da formação jurídico-institucional, a pouca existência de Conselhos temáticos de meio ambiente, o contrário de Desenvolvimento Rural Sustentável em que estão formalmente instituídos em 14 (quatorze) municípios desse território, porém o funcionamento segue em apenas seis. A disparidade entre a quantidade desses dois tipos de Conselhos pode ser constatada pelos processos decisórios, podendo ser explicada pela discussão de maior incidência ser relacionada à programas de repasses financeiros (ex. Garantia SAFRA), ou seja, a existência e o funcionado podem estar atrelados ao funcionamento, execução e existência de políticas públicas rurais.

Dentre as questões relacionadas ao processo decisório pode-se destacar que, embora se tenha na formação e estruturação desses Conselhos equidade em relação aos membros (poder público e sociedade civil), na prática não se observa tanta coerência, pois as decisões, em sua maioria, envolvem questões administrativas e burocráticas, as quais dizem respeito à própria gestão pública.

Por fim, as limitações desta pesquisa estão relacionadas ao próprio processo de coleta de dados, devido ao tempo do fornecimento das informações pelos municípios sobre os conselhos e documentos relacionados às reuniões, havendo ainda algumas informações que não foram possíveis devido à falta de comunicação. A partir disso, sugere como estudos futuros analisar as fragilidades e as potencialidades da gestão participativa nas instituições deliberativas no que diz respeito ao acesso à participação na tomada de decisão e formulação de políticas ambientais sustentáveis, sob a ótica dos conselheiros municipais.

\section{Referências}

Avritzer, L. (2016). Impasses da democracia no Brasil. Civilização Brasileira.

Avritzer, L. (2009). Participatory institutions in democratic Brazil. Washington: Woodrow Wilson Center Press and The John Hopkins University Press.

Bardin, L. (2016). Análise de conteúdo. Edições 70.

Bobbio, N. (2000). O futuro da democracia. Trad. Marco Aurélio Nogueira. (7a. ed.), Paz e Terra.

Brasil. (1988). Constituição da República Federativa do Brasil: texto constitucional promulgado em 5 de outubro de 1988, compilado até a Emenda Constitucional no 106/2020. Brasília: Senado Federal, Coordenação de Edições Técnicas.

Brasil. (2011). Lei n. 12.527, de 18 de novembro de 2011. Regula o acesso a informações previsto no inciso XXXIII do art. $5^{\circ}$, no inciso II do $§ 3^{\circ}$ do art. 37 e no $\S 2^{\circ}$ do art. 216 da Constituição Federal; altera a Lei no 8.112, de 11 de dezembro de 1990; revoga a Lei no 11.111, de 5 de maio de 2005, e dispositivos da Lei $\mathrm{n}^{\circ}$ 8.159, de 8 de janeiro de 1991; e dá outras providências. Diário Oficial da República Federativa do Brasil, Brasília - DF, 18 nov. 2011 . Disponível em: http://www.planalto.gov.br/ccivil_03/_ato2011-2014/2011/lei/112527.htm. Acesso em: 17 abr. 2021.

Brasil. (2000). Decreto $n^{\circ}$ 3.508, de 14 de junho de 2000. Dispõe sobre o Conselho Nacional de Desenvolvimento Rural Sustentável - CNDRS, e dá outras providências. Diário Oficial da República Federativa do Brasil, http://www.planalto.gov.br/ccivil_03/decreto/D3508impressao.htm Acesso em: 21 abr. 2021.

Bordignon, G. \& Gracido, R. V. (2006). Gestão da educação: o município e a escola. In: Ferreira, N. S. C.; Aguiar, M. Â. S. (Orgs.). Gestão da educação: impasses, perspectivas e compromissos. Cortez.

Cabral Neto, A., \& Macedo Filho, F. D. (2010). O Estado e o Dever de Proteção ao Meio Ambiente: a importância da participação social na formulação, execução e avaliação de políticas ambientais. In: Cabral Neto, A., Macedo Filho, F. D., \& Batista, M. S. S. (Orgs). Educação Ambiental: caminhos traçados, debates políticos e práticas escolares, p. 33-68. Líber Livros.

Cacimbas. (1998). Lei Municipal n. 08, de 13 de abril de 1998. Dispõe sobre a criação do Conselho De Desenvolvimento Rural e dá outras providências. 
Castro, A. M. D. A. (2009). A qualidade da educação básica e a gestão da escola. In: França, M., Bezerra, M. (Orgs.) (2009). Política Educacional: gestão e qualidade do ensino. Liber Livros, 2009.

Catingueira (2005). Lei Municipal n. 419, de 21 de dezembro de 2005. Dispõe sobre a reformulação do Conselho Municipal De Desenvolvimento Rural Sustentável de Catingueira e dá outras providências.

Catingueira (2012). Lei Municipal n. 532, de 28 de maio de 2012. Revoga a Lei n 419/2005 e institui um novo Conselho Municipal de Desenvolvimento Rural Sustentável e dá outras providências.

Condado (2012). Lei Municipal n. 377, de 8 de junho de 2012. Revoga a lei 181/1997, e institui o novo Conselho Municipal de Desenvolvimento Rural Sustentável - CMDRS e dá outras providências.

Condado (2013). Lei Municipal n. 389, de 10 de maio de 2013. Dispõe sobre a criação do Conselho Municipal de Meio Ambiente COMMAC e dá outras providências.

Dahl, R. A. (2001). Sobre a democracia. Editora Universidade de Brasília.

Dowbor, L. (2012). Democracia Econômica: um passeio pelas teorias. Vozes.

Facin, M. A., Soler, A. C. P., Veras Neto, F. Q., \& Machado, C. R. S. (2012). Conselhos ambientais: considerações para fomentar a educação ambiental. Revista Eletrônica do Mestrado em Educação, v. 28.

Ferreira, C. M. S., \& Fonseca, A. (2014). Análise da participação popular nos Conselhos Municipais de Meio Ambiente do Médio Piracicaba (MG). Ambiente \& Sociedade. 17(3), 239-258.

Creswell, J. W. W (2010). Projeto de pesquisa: métodos qualitativo, quantitativo e misto. (2a ed.), Bookman

Giaretta, J. B. Z., Fernandes, V., \& Philippi Jr., A. (2012). Desafios e condicionantes da participação social na gestão ambiental municipal no Brasil. Organizações \& Sociedade, 19, 527-548.

Gil, A. C. (2008). Métodos e técnicas de pesquisa social. (6a. ed.), Atlas.

Gohn. M. G. (2004). Empoderamento e participação da comunidade em políticas sociais. Saúde e Sociedade 13, 20-31.

Iberdrola (2019). Complexo Eólico da Paraíba: Paraíba reafirma nosso compromisso com a energia eólica onshore na América Latina. https://www.iberdrola.com/quem-somos/linhas-negocio/projetos-emblematicos/complexo-eolico-terrestre-paraiba

Lenzi, C. L. (2009). A política democrática da sustentabilidade: os modelos deliberativo e associativo de democracia ambiental. Ambiente \& Sociedade, 12, $19-36$.

Loureiro, C. F. B., \& Cunha, C. C. (2008). Educação ambiental e gestão participativa de unidades de conservação: elementos para se pensar a sustentabilidade democrática. Ambiente \& Sociedade 11, 237-253.

Mãe D'água. (1998). Lei Municipal n. 141/98, de 09 de abril de 1998. Dispõe sobre a criação do Conselho de Desenvolvimento Rural Sustentável (CMDRS) e dá outras providências.

Mãe D'água. (2012). Lei n. 401/2012, de 27 de novembro de 2012. Dispõe sobre a reformulação do Conselho de Desenvolvimento Rural Sustentável (CMDRS) e dá outras providências.

Malta. (1996). Lei Municipal n. 06, de 16 de dezembro de 1996. Cria o Conselho Comunitário de Desenvolvimento da Agricultura do município e dá outras providências.

Manzini-Covre, M. L. (2002). O que é cidadania. Brasiliense.

Marques, P. E. M., \& Flexor, G. (2008). Conselhos municipais e políticos de desenvolvimento rural: questões em torno do debate sobre os papéis sociais e ambientais da agricultura. Revista eletrônica Sociedade e Desenvolvimento Rural-INAGRO, p. 45-66.

Maturéia (1997). Lei Municipal n. 056, de 03 de novembro de 1997. Cria o Conselho Municipal de Conservação e Defesa do Meio Ambiente - COMDEMA e dá outras providências.

MMA. Ministério de Meio Ambiente (2020). Desenvolvimento Rural Sustentável. https://www.mma.gov.br/desenvolvimento-rural.html.

MDA. Ministério do Desenvolvimento Agrário (2020). Sistema de Informações Territoriais. Território Médio Sertão-PB. http://sit.mda.gov.br/download/ptdrs/ptdrs_qua_territorio059.pdf.

Morais, L. A. (2017). Conselhos Ambientais: Uma análise do processo de participação de conselheiros municipais no Território Açu-Mossoró-RN. 2017. 204f. Dissertação (Mestrado) - Programa de Pós-Graduação em Ambiente, Tecnologia e Sociedade, Universidade Federal Rural do Semi-Árido. Mossoró.

Morais, L. A., Siqueira, E. S., Siqueira Filho, V., \& Nepomuceno, L. H. (2021). Dynamics of social participation in the Municipal Environmental Council of the Açu-Mossoró Territory (RN): Reality from a documentary perspective. Research, Society and Development, 10, e19910515079.

Nascimento, T. S. S., Souza, F. O., Morais, L. A., \& Carvalho, E. F. (2020). Percepção dos impactos socioambientais da energia eólica no sertão Paraibano. Revista Brasileira de Meio Ambiente, 8. 99-109.

Paiva, C. O. L. (2020). A Temática Ambiental Na Educação Integral: Política, Currículo E Práticas Educativas Nas Escolas Em Tempo Integral Do Rio Grande Do Norte. 2020. 142f. Dissertação (Mestrado) - Programa de Pós-Graduação em Ensino, Universidade do Estado do Rio Grande do Norte. Pau dos Ferros-RN, 2020. 
Research, Society and Development, v. 10, n. 7, e43510716639, 2021

(CC BY 4.0) | ISSN 2525-3409 | DOI: http://dx.doi.org/10.33448/rsd-v10i7.16639

Patos. (2000). Lei Municipal n. 2.985, de 20 de novembro de 2000. Cria o Conselho Municipal do Meio Ambiente e dá outras providências.

Patos. (2009). Lei Municipal n. 3.778, de 19 de junho de 2009. Revogam as leis: 3.436/2005 de 15/08/2005; 2.542/98 de 01106/1998; 2.217/95 de 16/11/1995, relacionadas com o Conselho Municipal de Desenvolvimento Agropecuário de Patos, e institui novo conselho, e dá outras providências.

Quixaba. (2012). Lei Municipal n. 303, de 25 de junho de 2012. Institui o Conselho Municipal De Desenvolvimento Rural Sustentável do município de Quixaba-PB, revoga a lei n 221/2009, de 27 de abril de 2009, e dá outras providências.

Salgadinho. (2007). Lei Municipal n. 079/2007 de 29 de novembro de 2007. Dispõe sobre modificação da Lei de No 052/2005 de um de junho de 2005 que institui o Conselho de Desenvolvimento Rural Sustentável (CMDRS) do município de Salgadinho-PB e dá outras providências.

Santa Terezinha. (2012). Lei Municipal n. 397, de 28 de maio de 2012. Revoga as leis municipais 026/1998 de 12 e abril de 1998 e $286 / 2005$ de 20 de maio de 2005, e institui o Novo Conselho Municipal De Desenvolvimento Rural Sustentável - CMDRS e agregando objetivos e diretrizes do conselho do programa de redução da pobreza rural - PRPR e dá outras providências.

Santin, J. R., \& Pandolfo, B, P. (2016). Participação e conselhos gestores municipais. RBHCS - Revista Brasileira de História \& Ciências Sociais, 8(16).

Santos, M. R. A., \& Paes, D. C. (2020). Liderança situacional e meio ambiente: análise do grau de maturidade do Conselho Municipal de Meio Ambiente de Santa Maria. Research, Society and Development, $9(3)$.

São José do Sabugi. (2005). Lei Municipal n. 396, de 20 de maio de 2005. Reformular o Conselho Municipal de Desenvolvimento Rural Sustentável do município de São José do Sabugi e dá outras providências.

São José do Sabugi. (2011). Lei Municipal n. 449, de 27 de outubro de 2011. Institui o Novo Conselho Municipal de Desenvolvimento Rural Sustentável CMDRS e dá outras providências.

Sen, A. (2010). Desenvolvimento como liberdade. Companhia das Letras, 2010.

Souza, D. B.; \& Novicki, V. (2011). A participação social na questão ambiental: limites e possibilidades nos Conselhos de Meio Ambiente no Brasil. EccoS. Revista Científica, 25, 235-249.

Tatagiba, L. (2002). Os conselhos gestores e a democratização das políticas públicas no Brasil. In: DAGNINO, Evelina (Org.). Sociedade civil e espaços públicos no Brasil. Paz e Terra.

Teixeira. (2012). Lei Municipal n. 197, de 4 de junho de 2012. Institui um novo Conselho Municipal de Desenvolvimento Rural Sustentável - CMDRS e dá outras providências.

Várzea. (2011). Lei Municipal n. 015, de 1 de dezembro de 2011. Altera a lei $n^{\circ}$ 05/1998, que dispõe sobre a instituição do Conselho Municipal De Desenvolvimento Rural Sustentável - CMDRS, e dá outras providências.

Vergara, S. C. (2016). Projetos e relatórios de pesquisa em administração. Atlas, 2016.

Vista Serrana. (2009). Lei Municipal n. 011, de 16 de junho de 2009. Dispõe sobre a modificação do atual Conselho Municipal de Desenvolvimento Rural Sustentável-CMDRS, e dá outras providências.

WEG S. A. (2019). WEG - Parque solar Angico e Malta. 1 vídeo (2:22). Publicado pelo canal Weg S.A https://www.youtube.com/ watch?v=nEGTdGK0AMw\&app=desktop. 